\title{
Severe outbreak of bovine neonatal diarrhea in a dairy calf rearing unit with multifactorial etiology
}

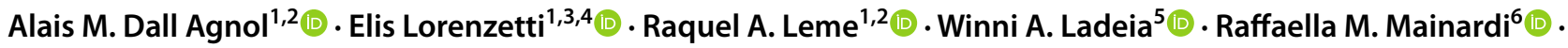

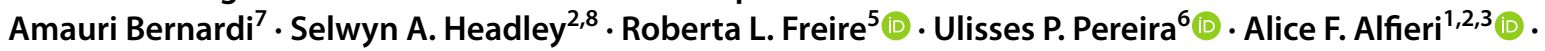 \\ Amauri A. Alfieri ${ }^{1,2,3}$
}

Received: 28 February 2021 / Accepted: 27 June 2021 / Published online: 9 July 2021

(c) Sociedade Brasileira de Microbiologia 2021

\begin{abstract}
This study describes the etiological diversity observed in a severe neonatal diarrhea outbreak with morbidity and mortality rates of 80 and 20\%, respectively, with detection of mixed infections with viral, bacterial, and protozoan disease agents in a dairy calf rearing unit. Diarrheic fecal samples were collected from eight 5 to 18 days of age calves and were submitted to the investigation of the presence of rotavirus A (RVA), bovine coronavirus (BCoV), bovine kobuvirus (BKV), bovine viral diarrhea virus 1 and 2 (BVDV-1 and BVDV-2), enteropathogenic Escherichia coli (ETEC), Salmonella sp., and Cryptosporidium spp. Fragments of the small intestine of one calf with diarrhea that spontaneously died were submitted for histopathological analyses. The most frequent infectious agent detected in diarrheic fecal samples was BKV (8/8-100\%), followed by RVA (5/8-62.5\%), BVDV (5/8-62.5\%), Cryptosporidium parvum (5/8-62.5\%), ETEC (4/8-50\%), and Cryptosporidium ryanae (1/8-12.5\%). These etiological agents were found in mixed infections with two or more pathogens per diarrheic fecal sample. The association of viral and protozoan pathogens was the most frequently identified (37.5\%) in these samples, followed by viral and bacterial (25\%); viral, bacterial, and protozoan (25\%); and only viral agents (12.5\%). BCoV and Salmonella sp. were not identified in the diarrheic fecal samples analyzed. Additionally, histopathology of the small intestine diagnosed chronic lymphocytic enteritis. In conclusion, in calf rearing units, the adoption and strict monitoring of health management practices are critical to the success of this calf creation system.
\end{abstract}

Keywords Dairy herd $\cdot$ Mixed infection $\cdot$ Rotavirus $\cdot$ Kobuvirus $\cdot$ E. coli $\cdot$ Cryptosporidium spp.

Amauri A. Alfieri

alfieri@uel.br

1 Laboratory of Animal Virology, Department of Veterinary Preventive Medicine, Universidade Estadual de Londrina, Londrina, Paraná, Brazil

2 National Institute of Science and Technology of Dairy Production Chain (INCT-Leite), Universidade Estadual de Londrina, Londrina, Paraná, Brazil

3 Multi-User Animal Health Laboratory, Molecular Biology Unit, Department of Veterinary Preventive Medicine, Universidade Estadual de Londrina, Londrina, Paraná, Brazil

4 Post Graduate Program in Animal Health and Production, Universidade Pitágoras Unopar, Arapongas, Paraná, Brazil
5 Laboratory of Protozoa, Department of Veterinary Preventive Medicine, Universidade Estadual de Londrina, Londrina, Paraná, Brazil

6 Laboratory of Animal Bacteriology, Department of Veterinary Preventive Medicine, Universidade Estadual de Londrina, Londrina, Paraná, Brazil

7 Autonomous zootechnician, Paraná, Brazil

8 Laboratory of Animal Pathology, Department of Veterinary Preventive Medicine, Universidade Estadual de Londrina, Londrina, Paraná, Brazil 


\section{Introduction}

Neonatal calf diarrhea (NCD) is the most important cause of economic losses to dairy and beef cattle herds worldwide, due to growth disorders, cost of treatment, and/or death of sick animals [1]. The main age group affected by enteric disorders are calves up to 30 days of age [2]. The etiology of the NCD is complex and is considered a multifactorial disease due to the combination of predisposing factors and a variety of infectious disease agents that are involved $[2,3]$. Predisposing factors associated with the development of NCD include age, genetics, unfavorable environmental conditions, inadequate management, poor nutrition, inefficient immune status, and concomitant diseases $[4,5]$.

The infectious disease pathogens associated with the development of NCD can be divided into viral, bacterial, and protozoa agents. Rotavirus A (RVA), bovine coronavirus (BCoV), bovine kobuvirus (BKV), and bovine viral diarrhea virus 1 and 2 (BVDV-1 and BVDV-2) are the more frequently viral pathogens associated with the development of NCD [6-10]. The most common bacterial agents are enteropathogenic Escherichia coli (ETEC) and Salmonella sp. [11], while Cryptosporidium spp. and Eimeria spp. are the most frequent protozoa detected in NCD outbreaks $[12,13]$. Although these pathogens acting individually have been considered as primary agents of enteric disorders, currently, there is an increase in concomitant infections due to several microorganisms in the development of NCD $[2,3]$.

Dairy calf rearing units were implemented by cooperative societies of dairy producers in southern Brazil to accelerate the development of calves and heifers, during which calves not more than 5-day-old are received from different dairy farms and pregnant heifers are returned to original farms [8]. However, information relative to the immunological and health status of these animals and the health consequences of this form of breeding is lacking. Consequently, this study describes the etiological diversity observed in a severe neonatal diarrhea outbreak and the detection of mixed infections with viral, bacterial, and protozoan disease agents in a dairy calf rearing unit.

The farm under study consisted of a Holstein breed heifer and calf rearing unit with a total of 948 animals located in the Western of Paraná State, Southern Brazil. This calf rearing unit receives 3- to 4-day-old calves that are separated from their respective dams soon after birth, from nine distinct dairy cattle herds. During milk-feeding, all calves are maintained in collective pens; however, after weaning, the calves are transferred to grass pickets until returned to their original herds, which occurs after artificial insemination and the confirmation of pregnancy.
Although vaccination for the control of neonatal diarrhea by RVA, BCoV, and ETEC is recommended at the final stage of pregnancy, some original herds do not perform immunizations. The commercial vaccine that is used by some of the original herds that provide calves to the calf rearing unit contains E. coli K99 and J5, Salmonella dublin, BVDV-1 and BVDV-2, bovine respiratory syncytial virus, bovine alphaherpesvirus 1 and 5, bovine parainfluenza virus 3, Mannheimia haemolytica, and Pasteurella multocida. The dairy calf rearing unit recommends to the original herds that intake of colostrum starts until $1 \mathrm{~h}$ after calving birth and should be in an adequate quantity for all newborn calves (corresponding to $10 \%$ of the calf's weight at the first feeding); however, this recommendation is not heeded by all owners of the original herds. The level of passive immunity transfer in the calves was not assessed at the rearing unit.

In April 2019, a severe neonatal diarrhea outbreak was reported at this dairy calf rearing unit. Clinical signs were observed in 3- to 4-day-old calves shortly after the arrival at the calf rearing unit. The diarrhea outbreak affected calves up to 4 weeks of age and contained 120 animals up to this group. Initially, most calves had severe watery diarrhea that resulted in dehydration, with anorexia, depression, and fever for approximately five days. Additionally, some calves died 5 to 10 days after the onset of diarrhea. Some affected animals were treated with broad-spectrum antibiotic therapy (florfenicol and ceftiofur), but without any clinical improvement. During the neonatal diarrhea outbreak, morbidity $(80 \% ; 96 / 120)$ and mortality $(20 \%$; 24/120) rates were elevated.

Diarrheic fecal samples were collected from eight calves with 5 to 18 days of age. These evaluated calves did not receive any type of therapy for the treatment of NCD. One calf with clinic signs of diarrhea that spontaneously died was autopsied at the rearing unit. All diarrheic feces and fragments of the small intestine were collected and submitted for microbiological and/or histopathological analyses.

Fecal suspensions at 10 to $20 \%$ (weight/volume) were submitted to nucleic acid extraction using a combination of phenol/chloroform/isoamyl alcohol (25:24:1) and silica/ guanidinium isothiocyanate methods [14]. The RNA presence of RVA, BVDV-1 and BVDV-2, and BKV was investigated by RT-PCR assays and BCoV RNA by semi-nestedRT-PCR assay. The amplifications were performing using primers that targeted the RVA VP7 and VP4 genes [15, 16], BCoV N gene [17], BVDV 5' UTR genomic region [18], and BKV 3D [19] and VP1 [20] genes. Aliquots of sterile ultrapure diethylpyrocarbonate-treated water were included as negative controls in all procedures. Samples previously known as positive for each of the virus investigated in this study were included as positive controls: prototype NADL and Mebus strains cell culture (Madin-Darby bovine kidney) 
adapted for BVDV and BCoV, respectively, and fecal samples known to be positive for RVA [9] and BKV [21].

The isolation of $E$. coli from rectal swabs was performed on Mueller Hinton agar enriched with defibrinated sheep blood and MacConkey agar, both incubated for $24 \mathrm{~h}$ at $37^{\circ} \mathrm{C}$. Suggestive colonies of E. coli, obtained from each fecal sample, were identified by their morphological and biochemical characteristics, and thereafter submitted to DNA extraction [22]. To classify the isolates as diarrheagenic $E$. coli strains, five colonies of each rectal swab were subjected to a multiplex-PCR assay designed to detect 10 different virulence genes (stxl, stx2, eae, bfpA, invE, aggR, esth, estp, $e l t$, and astA) [23]. Antimicrobial susceptibilities tests were performed on Mueller Hinton agar by using the disc diffusion method described by Kirby and Bauer methodology according to international standardization (CLSI, 2012), including the following antibiotics: ceftiofur $(30 \mu \mathrm{g})$, chloramphenicol (30 $\mu \mathrm{g})$, enrofloxacin $(5 \mu \mathrm{g})$, florfenicol (30 $\mu \mathrm{g})$, gentamicin $(10 \mu \mathrm{g})$, sulfazotrim $(25 \mu \mathrm{g})$, and tetracycline $(30 \mu \mathrm{g})$.

The detection of Salmonella sp. DNA was performed directly from the nucleic acid extracted from the feces [14], by using a PCR assay designed to amplify the $i n v A$ virulence gene [24].

Oocysts of Cryptosporidium spp. detected from the diarrheic fecal samples were submitted to the modified Ziehl-Neelsen technique, and the whole slide was read [25, 26]. Semiquantitative and quantitative technique were used to estimate the oocysts concentration in fecal samples. The semiquantitative mensuration was achieved by using five predetermined scores 0 (no oocysts), 1 (1-3 oocysts per slide), 2 (3-5 oocysts per field of slide), 3 (6-10 oocysts per field of slide), and 4 (>10 oocysts per field of slide) as previously described [27]. To estimate oocysts per gram of feces, the total oocysts counted per slide was divided by the weight of feces per slide (in grams) using the following formula:

oocysts per gram of feces $=\frac{\text { total oocysts per slide }}{\text { weight of feces per slide }(g)}$

The nucleic acid of the positive fecal sample was extracted by a commercial kit (NucleoSpin Tissue $\AA$, Macherey Nagel, Düren, Germany) to determine the species of Cryptosporidium in infected animals. The DNA was submitted to a nested-PCR assay designed to amplify the SSU rRNA gene [28], and the target sequence was then submitted to restriction fragment length polymorphism technique $[29,30]$. The length of fragments was visualized by agarose gel electrophoresis and compared with previously described sequences [29, 30].

Tissue fragments of the small intestine collected at the calf rearing unit were fixed by immersion in $10 \%$ buffered formalin solution and then routinely processed with the hematoxylin and eosin $(\mathrm{H} \& \mathrm{E})$ stain for histopathologic evaluation.

To confirm the specificity of the PCR amplicons and to determine the $\mathrm{G}$ and $\mathrm{P}$ genotypes of RVA and subgenotypes of BVDV, two amplified products of each viral pathogen RVA (VP4 and VP7 genes), BKV (VP1 gene), and BVDV (5'UTR region), from different fecal samples, were selected for sequencing analyzes. The PCR amplicons were purified by the PureLink® Quick Gel Extraction and PCR Purification Combo Kit (Invitrogen ${ }^{\circledR}$ Life Technologies, Carlsbad, CA, USA), quantified using a Qubit ${ }^{\circ}$ Fluorometer (Invitrogen ${ }^{\circledR}$ Life Technologies, Eugene, OR, USA), and sequenced in both directions with the same forward and reverse primers used in the molecular assays on an ABI3500 Genetic Analyzer sequencer with the BigDye Terminator v3.1 Cycle Sequencing Kit (Applied Biosystems ${ }^{\circledR}$, Foster City, CA, USA). Sequence quality analyses and consensus sequences were obtained using PHRED and CAP3 software (http://asparagin.cenargen.embrapa.br/phph/), respectively. Similarity searches were performed with nucleotide (nt) sequences deposited in GenBank using the Basic Local Alignment Search Tool software (https://blast.ncbi.nlm. nih.gov/Blast.cgi). Multiple and pairwise alignments with RVA, BKV, and BVDV strains available in GenBank were performed with MEGA software version 7.0.26 [31], and the nucleotide sequence identity matrices were constructed using the BioEdit software version 7.2.5 [32]. Phylogenetic trees based on the nt sequences were obtained using the neighbor-joining method [33] with the Kimura 2-parameter model [34] using MEGA software version 7.0.26 [31]. The bootstrapping probabilities were calculated using 1,000 replicates.

The most frequent infectious agent detected in diarrheic fecal samples during this study from newborn calves was BKV (100\%; 8/8), followed by RVA, BVDV, and C. parvum $(62.5 \% ; 5 / 8)$, ETEC $(50 \% ; 4 / 8)$, and C. ryanae $(12.5 \% ; 1 / 8)$ (Table 1). These etiological agents were identified in mixed infections that contained two or more pathogens per fecal sample. The association of viral and protozoan pathogens was the most frequently identified (37.5\%) in the fecal samples, followed by viral and bacterial (25\%); viral, bacterial, and protozoan (25\%); and only viral agents (12.5\%). Nucleic acids of BCoV and Salmonella sp. were not identified in any of the diarrheic fecal samples analyzed.

Escherichia coli was isolated from all fecal samples analyzed, but virulence genes were found in only $50 \%$ $(4 / 8)$ of the samples and were classified as ETEC strains. The in vitro microbial sensitivity profile of $E$. coli isolates from the calves with diarrhea showed $95.2 \%$ sensitivity to ceftiofur, $42.8 \%$ to florfenicol and gentamicin, $38.1 \%$ to sulfazotrim, $28.6 \%$ to chloramphenicol and enrofloxacin, and $9.5 \%$ to tetracycline. Regarding Cryptosporidium spp., a range of 33 to 215,066 oocysts per gram of feces were 
Table 1 Microorganisms (virus, bacteria, and protozoa) identified in a severe neonatal diarrhea outbreak in a dairy calf rearing unit from Southern Brazil

\begin{tabular}{|c|c|c|c|}
\hline Fecal sample & $\begin{array}{l}\text { Calf age } \\
\text { (days) }\end{array}$ & Mixed infection & Sequenced amplicons \\
\hline 1 & 5 & $\mathrm{BKV}+\mathrm{RVA}+\mathrm{BVDV}+\mathrm{ETEC}$ & $\mathrm{BVDV}^{\mathrm{a}}$ \\
\hline 2 & 11 & $\mathrm{BKV}+\mathrm{RVA}+\mathrm{BVDV}+$ C. parvum & $\mathrm{BVDV}^{\mathrm{b}}, \mathrm{BKV}^{\mathrm{c}}$ \\
\hline 3 & 11 & $\mathrm{BKV}+\mathrm{RVA}+\mathrm{BVDV}+\mathrm{ETEC}+$ C. parvum & $\mathrm{RVA}^{\mathrm{d}}$ \\
\hline 4 & 5 & $\mathrm{BKV}+\mathrm{RVA}+\mathrm{ETEC}$ & - \\
\hline 5 & 18 & $\mathrm{BKV}+\mathrm{RVA}+C \cdot$ parvum & $\mathrm{RVA}^{\mathrm{e}}$ \\
\hline 6 & 11 & $\mathrm{BKV}+\mathrm{BVDV}$ & $\mathrm{BKV}^{\mathrm{f}}$ \\
\hline 7 & 11 & $\mathrm{BKV}+\mathrm{BVDV}+$ C. parvum + C. ryanae & - \\
\hline 8 & 13 & $\mathrm{BKV}+\mathrm{ETEC}+C \cdot$ parvum & - \\
\hline
\end{tabular}

$R V A$, rotavirus A; $B K V$, bovine kobuvirus; ETEC, enterotoxigenic Escherichia coli; $B V D V$, bovine viral diarrhea virus; $C$. parvum, Cryptosporidium parvum; and C. ryanae, Cryptosporidium ryanae

Name of sequences and GenBank accession numbers: ${ }^{a}$ BRA/PR-2361/2019 (MT036102), bBRA/ PR-2364/2019 (MT036103), ${ }^{\mathrm{c} B R A / P R-2364 / 2019 ~(M N 539148), ~}{ }^{\mathrm{d} B R A / P R-2367 / 2019 ~(G 10: ~ M N 539146 ~}$ and P[11]: MN539147), ${ }^{\mathbf{e} B R A / P R-2362 / 2019 ~(G 10: ~ M N 539144 ~ a n d ~ P[11]: ~ M N 539145), ~ a n d ~}{ }^{\mathrm{BRA}}$ / PR-2365/2019 (MN539149) estimated in fecal samples analyzed. It is important to emphasize that the detection of E. coli and Cryptosporidium spp. were carried out by traditional microbiological and parasitological methods, respectively, so the detection rate may be underestimated in comparison with virus agents evaluated by molecular techniques.

Through phylogenetic analysis and nucleotide sequence identity matrices, the specificity of the amplicons (RVA, $\mathrm{BKV}$, and BVDV) obtained from the different diarrheic fecal samples was confirmed, and the G and P RVA genotypes and BVDV-1 subgenotypes were determined. Phylogenetic trees, nucleotide sequence identity matrices, GenBank accession numbers of each viral strain identified in this study, and representative strains for each virus were presented in the Online Resource. Comparative analyzes of the sequences of the VP7 and VP4 genes obtained in this study with representative strains of 36 known RVA G genotypes and 51 known RVA P genotypes, respectively, were performed, and RVA G10P[11] genotype combination was identified in two fecal samples ( $n^{\circ} 3$ and 5) from this study and was named BRA/PR-2362/2019 and BRA/ PR-2367/2019 (Supplementary Fig. 1 and Table S1 genotype G and Supplementary Fig. 2 and Table S2 genotype $\mathrm{P}$ ). The comparative analysis between the strains identified herein and with 20 other kobuvirus strains was performed, and BKV strains derived from fecal samples $\mathrm{n}^{\circ} 2$ and 6 were named BRA/PR-2364/2019 and BRA/ PR-2365/2019, respectively (Supplementary Fig. 3 and Table S3). The two wild-type BVDV 5'UTR sequences identified in this study were compared with representative strains of 21 BVDV-1 subgenotypes and were classified as BVDV-1b and BVDV-1d subgenotype and named as BRA/ PR-2361/2019 (fecal sample ${ }^{\circ}{ }^{\circ}$ ) and BRA/PR-2364/2019 (fecal sample $n^{\circ} 2$ ), respectively (Supplementary Fig. 4 and Table S4). Table 1 shows the distribution of the amplicons derived from the fecal samples analyzed and their respective GenBank accession numbers.

Histopathology of all intestinal segments evaluated had similar pathologic alterations with little variation between each sample. These lesions resulted in chronic lymphocytic enteritis due to mild blunting and fusion of intestinal villa, moderate accumulation of lymphocytes at the lamina propria, and mild cryptal dilation.

Rotavirus A was one of the most detected pathogens in this study and is the viral pathogen most frequently associated with NCD worldwide [2, 11, 14]. The combination of the G10P[11] genotype identified herein reinforces the data previously obtained that this genotype is the most frequent circulating in dairy herds in Brazil [9].

The exact role of BKV in the pathogenesis of diarrhea is not fully elucidated; however, the detection rate of BKV in fecal samples from calves with clinical signs is higher when compared with animals without clinic signs, reinforcing the participation of BKV in the pathogenesis of diarrhea [35]. In this study, BKV was identified in mixed infections, and similar findings were previously described [21, 36], suggesting that the occurrence of this virus may be associated with the concomitant presence of other diarrheic pathogens of cattle.

Bovine viral diarrhea virus is related to different clinical manifestations in cattle, including reproductive, respiratory, enteric disorders, and immunosuppression in infected animals [10]. Based on the high frequency of BVDV detection in the diarrheic fecal samples of this study and on the various effects that this virus can cause to the host, the possible immunosuppressive action of BVDV cannot be excluded [10], and, therefore, this may have contributed to the concomitant infections with other pathogens during the NCD outbreak.

In this study, Cryptosporidium spp. was one of the most detected enteric agents in calves infected. This protozoan 
is considered as a primary infectious agent associated with the development of NCD [12]. However, in mixed infection with other viral primary infectious disease agents, there is an increase in the severity of clinical signs and diarrheic cases in susceptible herds [37].

Enteropathogenic Escherichia coli is one of the most frequently identified microorganisms in calves with diarrhea worldwide [3]; among the diarrheagenic strains, ETEC is the most detected in newborn calves [38, 39]. In most cases, ETEC causes diarrhea during the first weeks of life, due to the ability to attach to enterocytes in young animals up to 2 weeks after birth [40] and frequently resulting in death [3, 11]. Most calves evaluated in this study were less than two weeks old, which may have contributed to the infection in these animals associated with ETEC.

Finally, the histopathologic findings observed in the small intestine are suggestive of viral-induced infections [3], while protozoan-associated disease was not identified probably due to differences in tissue samples submitted for histopathology and parasitology.

A high diversity of infectious agents as RVA, BKV, BVDV, ETEC, and Cryptosporidium spp. was detected in diarrheic fecal samples of calves in this study. The high frequency of mixed infection detection may be related to the diversity of the origin of the calf herds. When transferred to rearing units, these calves may present different immunological and microbiological profiles thus being a great challenge for health management which may be one of the risk factors for the occurrence of disease [41], including as NCD. Consequently, adequate health management is recommended to minimize the effects of the commingling of calves from different herds and to equal the immunological status. Other risk factors can influence the occurrence of NCD are related to the transport stress, changes in the environment and nutrition, associate to the immaturity of the immune system. These animals can arrive in the rearing unit with immunosuppression and may favor infection by one or more infectious agents, which can intensify the clinical manifestation [8].

The implementation of a regular vaccination program against the main enteric disease pathogens continues to be of the most important measures for the prevention of NCD. Most commercial vaccines available in Brazil have in their composition the most frequent RVA genotypes including G10 and P[11], which were detected in this NCD outbreak. In this study, the vaccination of pregnant cows against enteric pathogens was not a routine practice used by all dairy cattle herds, and no herd was vaccinated against RVA. If all original dairy cattle herds implemented a regular pregnant cow vaccination program, using more complete commercial vaccines for neonatal diarrhea control, in this case, also including the RVA G10P[11] genotypes that circulate on the farm, maybe, these infections could have been prevented and consequently decreased the losses caused by diarrhea outbreak. Therefore, good prevention measures to reduce NCD would be the vaccination of cows during the final gestational stage: moreover, early administration of good quality and quantity colostrum and routine cleaning and disinfection of the facilities of the breeding unit.

In conclusion, this study reports a severe NCD outbreak with high rates of morbidity and mortality in the risk group associate with mixed infections viruses, bacteria, and protozoa in a dairy calf rearing unit in Brazil. The commingling of calves from different herds may favor the transmission of several enteric pathogens, together with other predisposing factors present, increasing the immunological challenge of newborn calves, favoring the occurrence of severe enteric diseases. Thus, the implementation of health strategies directed for these rearing units, including immunization programs and adequate management measures, is necessary for the prevention of enteric diseases.

Supplementary Information The online version contains supplementary material available at https://doi.org/10.1007/s42770-021-00565-5.

Acknowledgements The authors thank the following Brazilian Institutes for financial support; the National Council of Technological and Scientific Development (CNPq); the Brazilian Federal Agency for Support and Evaluation of Graduate Education (CAPES); the Financing of Studies and Projects (FINEP); and the Araucaria Foundation (FAP/ $\mathrm{PR}$ ). AAA, AFA, and SAH are recipients of CNPq fellowships. RMM and LWA are recipients of the CAPES fellowship. EL is a recipient of the Funadesp fellowship. AMD is recipient of INCT-Leite/CAPES fellowship (grant number 88887.495081/2020-00).

Author contribution Conceptualization and design: AMD, AB, and AAA; sample collection, AB; viral analyses, AMD, EL, and RAL; protozoa analyses, WAL; bacterial analyses, RMM; histopathologic analysis, SAH; writing - original draft, AMD, EL, RAL, WAL, and RMM; supervision and writing - review and editing, SAH, RLF, UPP, AFA, and AAA. All authors have read and agreed to the published version of the manuscript.

Funding This work was supported by the National Institute of Science and Technology of Dairy Production Chain (CNPq/INCT-Leite) [grant number 465725/2014-7].

Data Availability GenBank accession numbers of strains of BVDV, BRA/PR-2361/2019 (MT036102) and BRA/PR-2364/2019 (MT036103); BKV, BRA/PR-2364/2019 (MN539148) and BRA/ PR-2365/2019 (MN539149); and RVA, BRA/PR-2367/2019 (G10: MN539146 and P[11]: MN539147) and BRA/PR-2362/2019 (G10: MN539144 and P[11]: MN539145).

\section{Declarations}

Ethics approval This study was approved by the Ethics Committee on the Use of Animals in Teaching and Research of the Universidade Estadual de Londrina (UEL), Londrina, Brazil, under number 6371.2013.43. All applicable international, national, and/or institutional guidelines for the care and use of animals were followed. 
Conflict of interest The authors declare no competing interests.

\section{References}

1. USDA (2018) Health and management practices on U.S. dairy operations, 2014. Accessed 06 April 2020

2. Gomez DE, Weese JS (2017) Viral enteritis in calves. Can Vet J 58(12):1267-1274

3. Cho YI, Yoon KJ (2014) An overview of calf diarrhea - infectious etiology, diagnosis, and intervention. J Vet Sci 15(1):1-17. https:// doi.org/10.4142/jvs.2014.15.1.1

4. McGuirk SM (2008) Disease management of dairy calves and heifers. Vet Clin North Am Food Anim Pract 24(1):139-153. https://doi.org/10.1016/j.cvfa.2007.10.003

5. Windeyer MC, Leslie KE, Godden SM, Hodgins DC, Lissemore KD, LeBlanc SJ (2014) Factors associated with morbidity, mortality, and growth of dairy heifer calves up to 3 months of age. Prev Vet Med 113(2):231-240. https://doi.org/10.1016/j.prevetmed. 2013.10.019

6. Cho YI, Han JI, Wang C, Cooper V, Schwartz K, Engelken T, Yoon KJ (2013) Case-control study of microbiological etiology associated with calf diarrhea. Vet Microbiol 166(3-4):375-385. https://doi.org/10.1016/j.vetmic.2013.07.001

7. Ribeiro J, Lorenzetti E, Alfieri AF, Alfieri AA (2014) Kobuvirus (Aichivirus B) infection in Brazilian cattle herds. Vet Res Commun 38(2):177-182. https://doi.org/10.1007/s11259-014-9600-7

8. Alfieri AA, Ribeiro J, de Carvalho BL, Lorenzetti E, Alfieri AF (2018) Dairy calf rearing unit and infectious diseases: diarrhea outbreak by bovine coronavirus as a model for the dispersion of pathogenic microorganisms. Trop Anim Health Prod 50(8):19371940. https://doi.org/10.1007/s11250-018-1592-9

9. Medeiros TNS, Lorenzetti E, Alfieri AF, Alfieri AA (2019) G and $\mathrm{P}$ genotype profiles of rotavirus A field strains circulating in beef and dairy cattle herds in Brazil, 2006-2015. Comp Immunol Microbiol Infect Dis 64:90-98. https://doi.org/10.1016/j.cimid. 2019.03.002

10. Ridpath JF (2010) Bovine viral diarrhea virus: global status. Vet Clin North Am Food Anim Pract 26(1):105-121. https://doi.org/ 10.1016/j.cvfa.2009.10.007

11. Izzo MM, Kirkland PD, Mohler VL, Perkins NR, Gunn AA, House JK (2011) Prevalence of major enteric pathogens in Australian dairy calves with diarrhoea. Aust Vet J 89(5):167-173. https://doi.org/10.1111/j.1751-0813.2011.00692.x

12. Thomson S, Hamilton CA, Hope JC, Katzer F, Mabbott NA, Morrison LJ, Innes EA (2017) Bovine cryptosporidiosis: impact, hostparasite interaction and control strategies. Vet Res 48(1):1-16. https://doi.org/10.1186/s13567-017-0447-0

13. Daugschies A, Najdrowski M (2005) Eimeriosis in cattle: current understanding. J Vet Med 52(10):417-427. https://doi.org/ 10.1111/j.1439-0450.2005.00894.x

14. Alfieri AA, Parazzi ME, Takiuchi E, Médici KC, Alfieri AF (2006) Frequency of group A rotavirus in diarrhoeic calves in Brazilian cattle herds, 1998-2002. Trop Anim Health Prod 38(78):521-526. https://doi.org/10.1007/s11250-006-4349-9

15. Gentsch JR, Glass RI, Woods P, Gouvea V, Gorziglia M, Flores J, Das BK, Bhan MK (1992) Identification of group A rotavirus gene 4 types by polymerase chain reaction. J Clin Microbiol 30(6):1365-1373. https://doi.org/10.1128/JCM.30.6.1365-1373. 1992

16. Gouvea V, Glass RI, Woods P, Taniguchi K, Clark HF, Forrester B, Fang ZY (1990) Polymerase chain reaction amplification and typing of rotavirus nucleic acid from stool specimens. J Clin Microbiol 28(2):276-282. https://doi.org/10.1128/JCM.28.2. 276-282.1990
17. Takiuchi E, Stipp DT, Alfieri AF, Alfieri AA (2006) Improved detection of bovine coronavirus $\mathrm{N}$ gene in faeces of calves infected naturally by a semi-nested PCR assay and an internal control. J Virol Methods 131(2):148-154. https://doi.org/10.1016/j.jviro met.2005.08.005

18. Vilcek S, Herring AJ, Herring JA, Nettleton PF, Lowings JP, Paton DJ (1994) Pestiviruses isolated from pigs, cattle and sheep can be allocated into at least three genogroups using polymerase chain reaction and restriction endonuclease analysis. Arch Virol 136(3-4):309-323. https://doi.org/10.1007/bf01321060

19. Reuter G, Boldizsar A, Pankovics P (2009) Complete nucleotide and amino acid sequences and genetic organization of porcine kobuvirus, a member of a new species in the genus Kobuvirus, family Picornaviridae. Arch Virol 154(1):101-108. https://doi.org/ 10.1007/s00705-008-0288-2

20. Yamashita T, Ito M, Kabashima Y, Tsuzuki H, Fujiura A, Sakae K (2003) Isolation and characterization of a new species of kobuvirus associated with cattle. J Gen Virol 84(11):3069-3077. https:// doi.org/10.1099/vir.0.19266-0

21. Ribeiro J, Lorenzetti E, Junior JCR, da Silva Medeiros TN, Alfieri AF, Alfieri AA (2017) Phylogenetic analysis of VP1 and RdRP genes of Brazilian aichivirus B strains involved in a diarrhea outbreak in dairy calves. Arch Virol 162(12):3691-3696. https://doi. org/10.1007/s00705-017-3531-x

22. Blanco M, Blanco JE, Rodríguez E, Abalia I, Alonso MP, Blanco J (1997) Detection of virulence genes in uropathogenic Escherichia coli by polymerase chain reaction (PCR): comparison with results obtained using phenotypic methods. J Clin Microbiol 31(1-2):3733. https://doi.org/10.1016/S0167-7012(97)00087-0

23. Fujioka M, Otomo Y, Ahsan CR (2013) A novel single-step multiplex polymerase chain reaction assay for the detection of diarrheagenic Escherichia coli. J Microbiol Methods 92(3):289-292. https://doi.org/10.1016/j.mimet.2012.12.010

24. Rahn K, De Grandis SA, Clarke RC, McEwen SA, Galan JE, Ginocchio C, Curtiss R 3rd, Gyles CL (1992) Amplification of an invA gene sequence of Salmonella typhimurium by polymerase chain reaction as a specific method of detection of Salmonella. Mol Cell Probes 6(4):271-279. https://doi.org/10.1016/08908508(92)90002-f

25. Ortolani EL (2000) Standardization of the modified ziehl-neelsen technique to stain oocysts of Cryptosporidium sp. Brazilian Journal of Veterinary Parasitology 9(1):29-31

26. Henriksen SA, Pohlenz JF (1981) Staining of cryptosporidia by a modified Ziehl-Neelsen technique. Acta Vet Scand 22(3-4):594-596

27. Robert B, Ginter A, Antoine H, Collard A, Coppe P (1990) Diagnosis of bovine cryptosporidiosis by an enzyme-linked immunosorbent assay. Vet Parasitol 37(1):1-8. https://doi.org/10.1016/ 0304-4017(90)90020-c

28. Xiao L, Morgan UM, Limor J, Escalante A, Arrowood M, Shulaw W, Thompson RC, Fayer R, Lal AA (1999) Genetic diversity within Cryptosporidium parvum and related Cryptosporidium species. Appl Environ Microbiol 65(8):3386-3391

29. Feng Y, Ortega Y, He G, Das P, Xu M, Zhang X, Fayer R, Gatei W, Cama V, Xiao L (2007) Wide geographic distribution of Cryptosporidium bovis and the deer-like genotype in bovines. Vet Parasitol 144(1-2):1-9. https://doi.org/10.1016/j.vetpar.2006.10. 001

30. Xiao L, Singh A, Limor J, Graczyk TK, Gradus S, Lal A (2001) Molecular characterization of cryptosporidium oocysts in samples of raw surface water and wastewater. Appl Environ Microbiol 67(3):1097-1101. https://doi.org/10.1128/aem.67.3.1097-1101. 2001

31. Kumar S, Stecher G, Tamura K (2016) MEGA7: molecular evolutionary genetics analysis version 7.0 for bigger datasets. Mol Biol Evol 33(7):1870-1874. https://doi.org/10.1093/molbev/msw054 
32. Hall T (1999) BioEdit: a user-friendly biological sequence alignment editor and analysis program for Windows 95/98/NT. Nucleic Acids Symp 41:98. https://doi.org/10.14601/phytopathol_medit err-14998u1.29

33. Saitou N, Nei M (1987) The neighbor-joining method: a new method for reconstructing phylogenetic trees. Mol Biol Evol 4(4):406-425. https://doi.org/10.1093/oxfordjournals.molbev. a040454

34. Kimura M (1980) A simple method for estimating evolutionary rates of base substitutions through comparative studies of nucleotide sequences. J Mol Evol 16(2):111-120. https://doi.org/10. 1007/bf01731581

35. Li H, Tang C, Yue H (2019) Molecular detection and genomic characteristics of bovine kobuvirus from dairy calves in China. Infect Genet Evol 74. https://doi.org/10.1016/j.meegid.2019. 103939

36. Jeoung HY, Lim JA, Jeong W, Oem JK, An DJ (2011) Three clusters of bovine kobuvirus isolated in Korea, 2008-2010. Virus Genes 42(3):402-406. https://doi.org/10.1007/s11262-011-0593-9

37. Al Mawly J, Grinberg A, Prattley D, Moffat J, Marshall J, French N (2015) Risk factors for neonatal calf diarrhoea and enteropathogen shedding in New Zealand dairy farms. Vet J 203(2):155-160. https://doi.org/10.1016/j.tvj1.2015.01.010
38. Younis EE, Ahmed AM, El-Khodery SA, Osman SA, El-Naker YF (2009) Molecular screening and risk factors of enterotoxigenic Escherichia coli and Salmonella spp in diarrheic neonatal calves in Egypt. Res Vet Sci 87(3):373-379. https://doi.org/10.1016/j. rvsc.2009.04.006

39. Holland RE (1990) Some infectious causes of diarrhea in young farm animals. Clin Microbiol Rev 3(4):345-375. https://doi.org/ $10.1128 / \mathrm{cmr} .3 .4 .345$

40. Foster DM, Smith GW (2009) Pathophysiology of diarrhea in calves. Vet Clin North Am Food Anim Pract 25(1):13-36. https:// doi.org/10.1016/j.cvfa.2008.10.013

41. Autio T, Pohjanvirta T, Holopainen R, Rikula U, Pentikäinen J, Huovilainen A, Rusanen H, Soveri T, Sihvonen L, Pelkonen S (2007) Etiology of respiratory disease in non-vaccinated, nonmedicated calves in rearing herds. Vet Microbiol 119(2-4):256265. https://doi.org/10.1016/j.vetmic.2006.10.001

Publisher's note Springer Nature remains neutral with regard to jurisdictional claims in published maps and institutional affiliations. 